\title{
Yahts Production, Traditional or Composite Materials, Advantages and Disadvantages
}

\author{
Mirela Koci \\ (PHD Candidate, Polytechnic University of Tirana), University “Ismail Qemali”, Vlore, Albania \\ Jorgaq Kacani \\ Academic, Prof. Dr, Dean of Polytechnic University of Tirana
}

\section{Abstract:}

In recent years, considerable progress has been made in understanding the characteristic of composite materials and their tailored structures in the marine environment. Processing and production sectors also have received more attention resulting in the potential for the construction of complex, large assemblies capable of withstanding heavy loads. However, the key challenges involved in employing composites for marine applications include the need for optimization of capital expenditure and operating costs of boats, ships and other marine artefact's constructed using composites. The aim of this paper there is to analise the mechanical parameters of different materials for yahts production, focusing to the different composite materials, bringing in evidence the advantages and disadvantages, taking in consideration the yaht architecture, comfort, efective cost production and manteinance.

Keywords: project design, structural analyse, composite materials, comfort, efective cost.

\section{Introduction}

The marine manufacturing industry for tourism and entertainment purposes is growing. Tourism, as a priority sector for our country and naturaly is foreseen to be developed and expanded in the future. Opportunities for the growth of nautical tourism are very high. Small and medium-sized manufacturing SMEs today need to be assisted in the production process in material selection, cost of production, comfort, safety standards in navigation. Composite materials that have started to be used in the production of tourist sailing yachts, especially those of the yacht type, have proven in practice the designers' expectations for the great advantages they have brought compared to steel. The performance of the new generation of this millennium will require the ever-increasing use of innovation and innovative materials that will spur scientific research in this field.

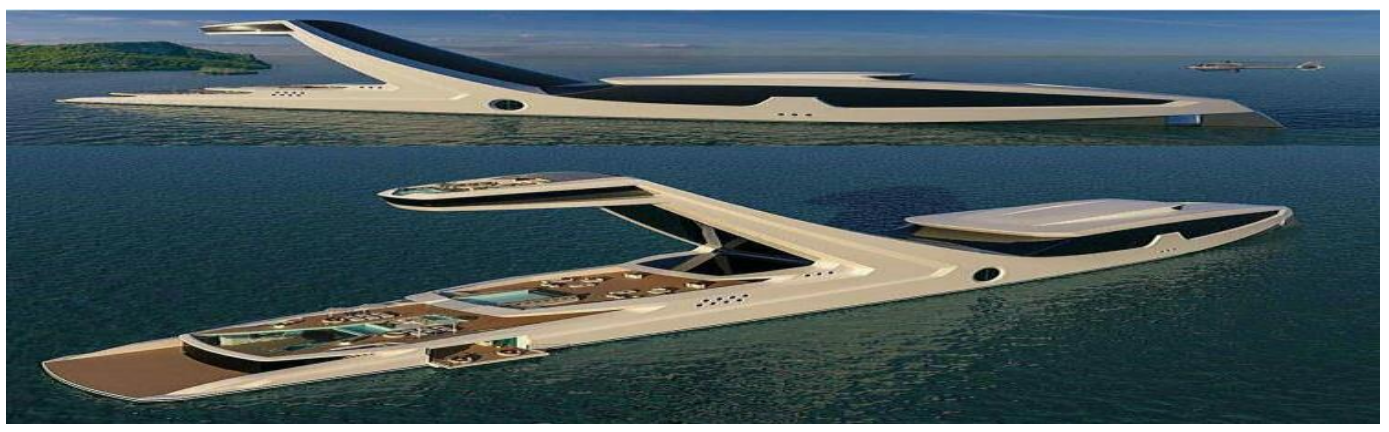

\section{General Considerations}

The characteristics of the carrying material should meet these requirements: 
- Specific weight: Must be as small as possible, responding to the characteristics of mechanical resistance, in order to achieve a lower weight of the shoe.

- Ability to save material over time: This implies resistance to the operation of the marine environment and consequently economy in maintenance.

- Labor Economic Optimisation: Optimisation on the cost of construction and the cost of production.

It is therefore necessary to individualize different materials, by their characteristics, thus evaluating the scope of use and not only the qualitative and work limitations.

In spite of this, in terms of the shipping sector used for recreational purposes (boats, yachts, yachts), we can say that, for a great use, they have found low-cost composite materials, such as resins Polyester reinforced fiberglass, especially in small size tools. This is due to the fact that through their use many advantages are achieved, among which we emphasize: the possibility of creating more and more complex forms and at the lowest cost; Good performance (are less susceptible to corrosion and microorganism damage); Small weight and consequently low maintenance costs; Easy to transport the vehicle, thanks to this small weight.

\section{III.1 Requirements for materials for yacht production}

\section{Weight}

As we have pointed out, Yahti's design and construction trends are those of realizing the final product with a total dislocation as small as possible. As is known from Archimedes' law, minimal deployment means the minimum diving volume of the vehicle, which, on the other hand, affects a lesser resistance to movement; Hidrodynamic features with a reduction of the surface area (in the case of sailing yachts), or motor power installed in the case of motor yachts; A better ride comfort; Reduction of construction costs and vehicle utilization; Increased navigation autonomy, especially in the case of large-scale vehicles.

\section{Vehicle stability}

If we look at the evolution of Yahti's seasonal shapes, and especially the megayachts with engines, we would point out that in these types of vehicles we have an ever-increasing tendency to utilize vertical vertical spaces, thus providing a greater number of Large envelopes in the interim part of the ship. This is because, as is known from the theory of hydrostaticism and stability of the ship, the addition of such ridges means a tendency to shift the center gravity of the ship from above. This, in turn, affects the deterioration of the ship's ship's stability characteristics as well as the problems associated with the longitudinal and wide winding of these vehicles, which means lowering the performance of these vehicles in terms of navigation and comfort.

\section{Evolution of forms and fulfillment of hydrodynamic characteristics}

The technical evolution of yacht type shapes has shown that one of the design solutions that satisfies their fulfillment is also the multi-hull marine. They are characterized by the fact that they have a central long and fin centerline, which is characterized by a small resistance to movement, as well as a more balanced distribution of moments at the time of the waveform being formed in the sea. The side skirts are of a smaller size to provide the vehicle with better stability and interference with the value systems created during the movement.

\section{Methodology}

For this stydy has been taken in consideration the data from International Register of Vehicles, part of Yahts. The metodology includes the elaboration of these data for the yahts between $30-50 \mathrm{~m}$ length produced with stell, alumin and composite materials. First of all heve been identified the level of use of composite materials in yahts production taking in consideration their use for entertiment proposal and their comfort, comparing the principal parameters like weight, thermal expantion, stiffness, strength and fatigue resistance identifying the advantages and disadvanteges of composite materials, elaborating and analysing the same parameters for different composite materials, as well as the life cicle of yahts compering with steel material. 


\section{Classification of marine vehicles produced in function of the material}

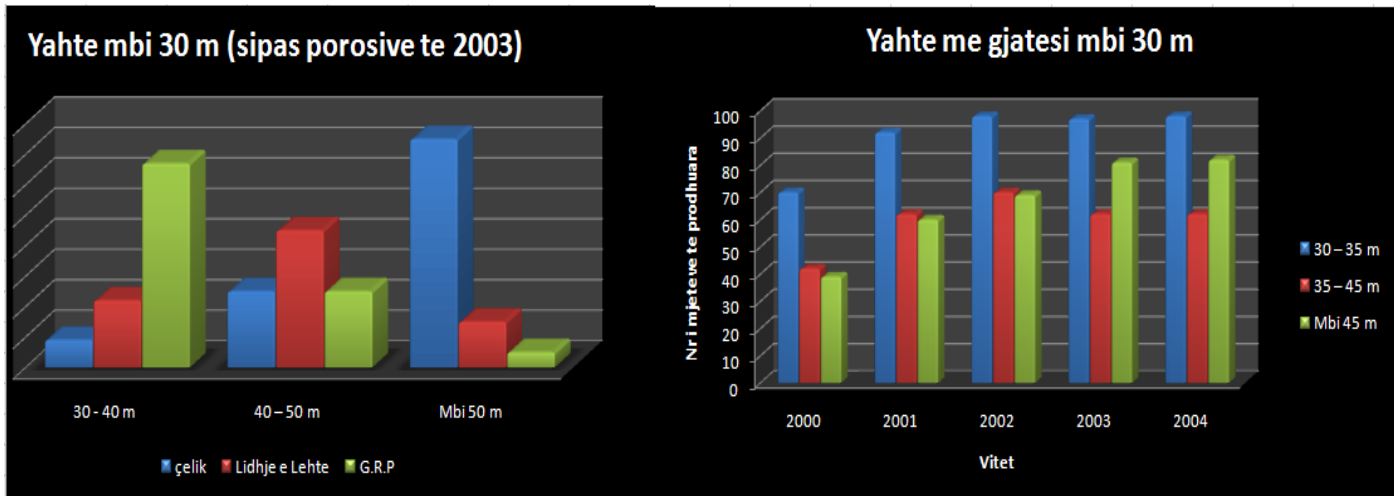

(Fig. No1 - Level of composite materials use for yahts 30-50 m length)

As can be seen, in the graphs presented above in the area of dimensions between $30-40 \mathrm{~m}$ in length, fiberglass covers almost $70 \%$ of the tools that are built.

And with the increase of length, and especially for a length greater than $50 \mathrm{~m}$, the most useful material is steel, which produces approximately $80 \%$ of the tools.

In the interval 40-50 m, where the distribution between materials is more uniform and we have no strong concentrations in the use of one or the other material.

This area of length is even more problematic with regard to yacht designers, as the Solas Norms may also be affected, which apply to yachts over $50 \mathrm{~m}$ long or over 500 tonnes.

The projectors of these vehicles tend to have an upper limit of $50 \mathrm{~m}$ in length to keep the vehicle's tire below the $500 \mathrm{t}$. The tendency to stay away from SOLAS norms is related to financial-normative factors.

However, it should be noted that in addition to the financial-normative factor, the designers of these yachts should also consider the factor of the operational costs of processing these materials.

This is because it is known that composite materials have undeniable advantage, which, in my opinion, will make this material in a very short dominant time even in this area of lengths

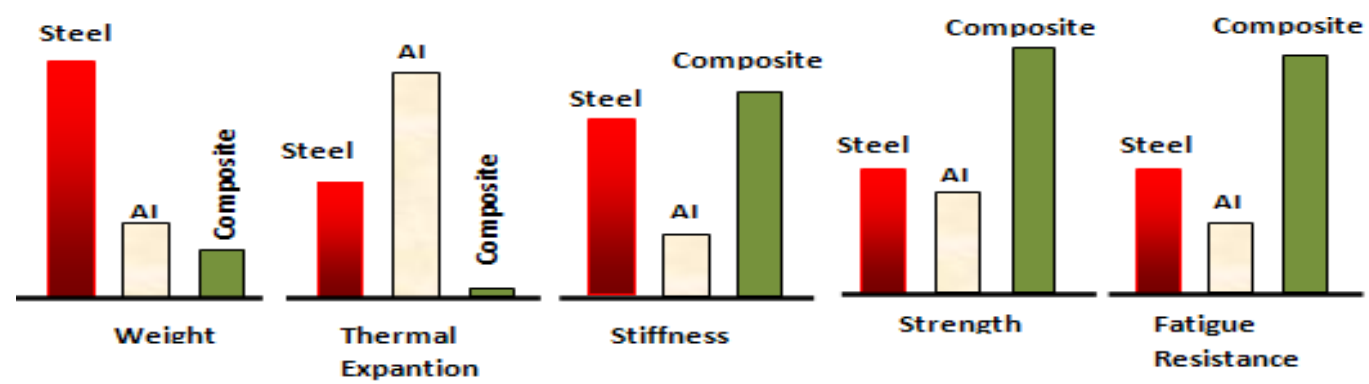

Fig. No2 - Mechanical parameters of composite, steel and aluminium materials

Another very important aspect, which can guide the choice of material, is the problem of economic cost. It includes the cost of raw materials and the processing of the material. The latter, on the other hand, involves difficulties in processing the material and consequently also the cost of processing machinery and the degree of professionalism of the site workers. 
Bearing in mind all the mechanical, economic and scale of mechanization of the yards, we can say that the floating industry for recreational purposes is predominated by the use of composite materials. The scope of application of these materials is particularly focused on surfing, yachting and fast boats. However, the evolution of composites can make this material dominant in other types of ships, such as fishing, military ships, and so on.

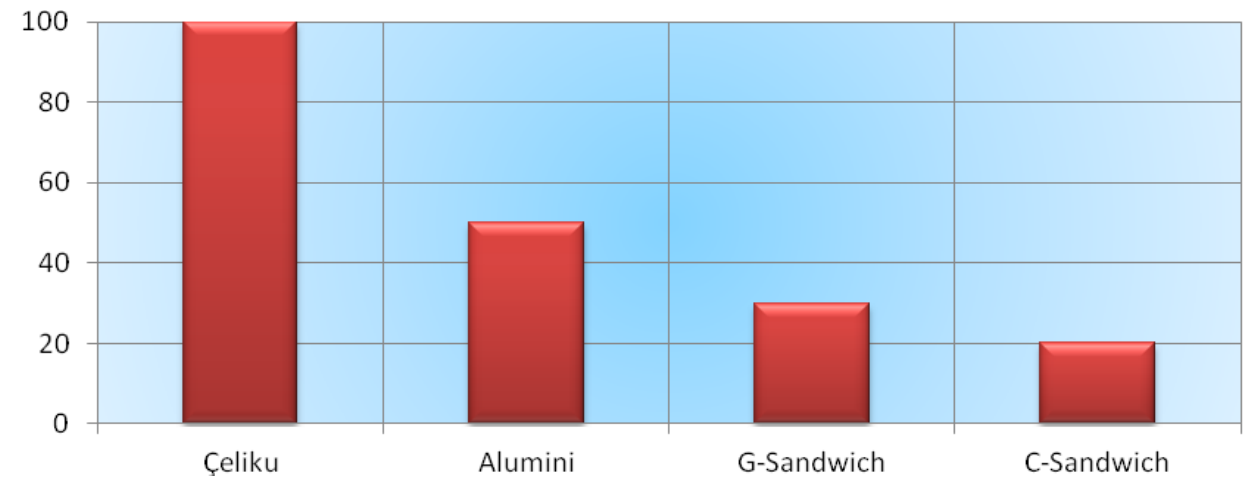

Fig. No3 - Weight saving as a result of the use of different materials

A yacht type with composite material can be constructed with a weight much easier than other materials (steel) and consequently this tool requires an installed power of up to $25 \%$ less for the same vehicle performance.

This makes it possible to choose an easier engine, creating better opportunities for its maintenance and repair. A smaller weight of the engine means even more access to other board accessories, thus increasing the degree of comfort.

A smaller installed power means even lower fuel consumption and, consequently, a lower cost of holding this vehicle from their owners. Understandably, the cost also depends on the hours of the cruise. The greater the time it is to use, the greater is the saving of monetary values.
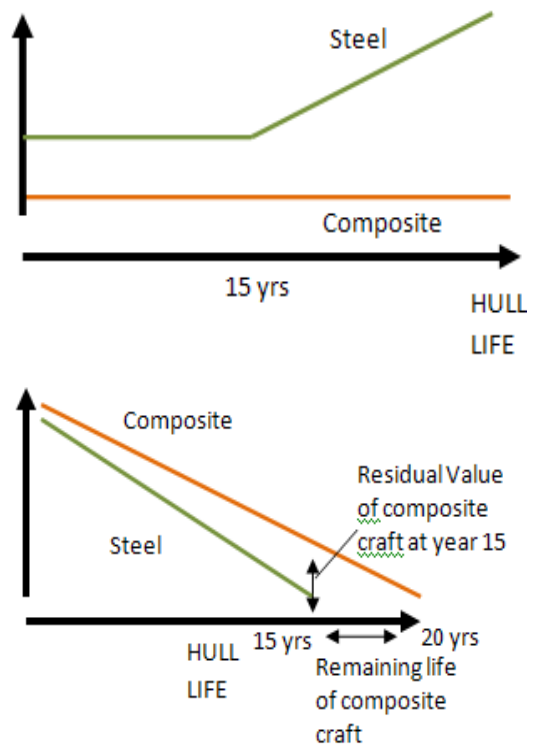

Fig No 4- Figure 4 shows a comparison between metal structures and composites 
Shelf Life. Steel and aluminum structures can guarantee an almost constant maintenance cost up to the first 15 years of service. Then its chart begins to grow very rapidly, as a result of steel corrosion and the appearance of cracks due to aluminum fatigue.

The current composite material production technologies have eliminated the osmosis phenomenon, making the tools maintain the aesthetic side, not exhibit structural degradation, and maintain the maintenance cost constant up to 20 years and more of the life cycle Of product.

A composite material tool, though generally having a higher cost of purchase, has a real internal value remaining in the 15 th year of life, with more years of lifespan for its use and less escalation of maintenance costs . Figure 4 shows graphically the residual value of the vehicle depending on the time of use

\begin{tabular}{|l|l|l|l|l|l|l|l|}
\hline \multicolumn{2}{|c|}{} & Fibre & \multicolumn{2}{l|}{ Resin } \\
\cline { 2 - 8 } & E-Xham & Aramide & $\begin{array}{l}\text { HS } \\
\text { Carbon }\end{array}$ & $\begin{array}{l}\text { HM } \\
\text { Carbon }\end{array}$ & Poliester & Epoksy \\
\hline Specific weight (g/cm2) & 2.54 & 1.45 & 1.80 & 1.9 & 1.20 & 1.20 \\
\hline $\begin{array}{l}\text { Jung's } \\
\text { Module } \\
\text { (N/mm2) }\end{array}$ & Parallel to fibers & 73000 & 130000 & 230000 & 370000 & 3000 & 2600 \\
\cline { 2 - 8 } & $\begin{array}{l}\text { Perpendicular to the } \\
\text { fiber }\end{array}$ & 73000 & 5400 & 15000 & 6000 & - & - \\
\hline Modul of Koulombit N/mm2 & 30000 & 12000 & 50000 & 20000 & - & - \\
\hline Poison Raport & 0,25 & 0,35 & 0,35 & 0,35 & 0,316 & 0,40 \\
\hline
\end{tabular}

\section{CONCLUSIONS}

From the analysis presented separately in the applicative part we conclude that composite materials represent a number of advantages compared to traditional materials of ship manufacturing.

1. Bearing in mind all the mechanical, economic and scale of mechanization of the site, we can say that the floating industry for recreational purposes is predominated by the use of composite materials.

2. In addition to the financial-normative factor, yacht designers should also consider the factor of operational costs of processing these materials.

3. If for the metal materials the physical-mechanical characteristics take different values depending on the type of bond, for the composite materials the main characteristics (including the specific weight) vary considerably, depending on the reinforcement, the percentage of saturation degree Glass (glass / slice ratio) and lamination (lamination) of the site.

4. The use of composite material in the production of yaht yachts means that yaht weight, creates the possibility of installing a motor fuse a few times smaller than the yaws produced with metal material, creates the possibility of increasing the comfort by adding accessories to the aredimin of Internally, increases the degree of comfort.

5. Low Cost of Maintenance and Renewal. The current composite material production technologies have eliminated the osmosis phenomenon, making the tools maintain the aesthetic side, not exhibit structural degradation, and maintain the maintenance cost constant up to 20 years and more of the lifecycle Of the product.

Non-linear features; Fire resistance; Small thermal conductance; High electrical resistance; Translucency to electromagnetic waves; Low light acoustic waves; Ease of use; Ease of integration with vehicle functions.

All of these features translated into effectiveness, durability, comfort. 


\section{Bibliography:}

[1] COMPARATIVE ANALYSIS OF MATERIALS IN RECREATIONAL BOAT DESIGN: FIBER REINFORCED PLASTIC BOAT IN SERIAL PRODUCTION, Serden GÖLPINAR

[2] Composite Materials in boats, Modern Composites used in Marine industry.

[3] Marine Composites, Second Edition, Eric Green Associates

[4] Green Ship Technology Book, European Marine Equipment Council

[5] ECO SHIP TECHNOLOGY. CLAss NK 